\title{
Microplastic tracking from Pacific garbage to Northern Indonesia Sea
}

\author{
Agung Ramos ${ }^{1}$; Noir P Purba ${ }^{1,2}$; Ibnu Faizal ${ }^{2}$; Yeni Mulyani ${ }^{1}$; \\ Mega L. Syamsuddin ${ }^{1}$ \\ ${ }^{1}$ Marine Science Program, Universitas Padjadjaran km. 21 UBR 40600, West Java
${ }^{2}$ Marine Reseacrh Laboratory (MEAL), Universitas Padjadjaran km. 21 UBR 40600,
West Java
}

e-mail correspondence: noir.purba@unpad.ac.id

\begin{abstract}
This study aims to examine the pattern of microplastic waste movement of Pacific Garbage Patch (PGP) that has the potential to enter the north of Indonesia sea. This study very important because microplastic affected the regional tourism activities, water pollution, and economics of fisherman and local society. The impact is very widerange to local and national economics. The method used is a simulation and descriptive analysis. The simulation method used is hydrodynamic simulation and trajectory of particles conducted for 365 days in 2016. The study areas in this study include eastern Indonesia, the Philippines, and the Pacific Ocean. The data used are wind, tidal, bathymetry, microplastic weight, and microplastic flux. The simulation results show the movement of microplastic at point source 1 tends to the northeast with a clockwise circular motion. The simulation results at source point 2 indicate that the microplastic movement tends to revolve around the source point in a clockwise circular motion. The result of simulation of source point 3 shows that the microplastic movement tends to the north with the circular motion and left-right movement. The displacement of microplastic particles within a year is only $0.11-8.94 \mathrm{~km}$ from the source point. This study showed that within a year, microplastic waste from PGP does not have the potential to enter the waters of Indonesia.
\end{abstract}

Keywords: Pasific garbage patch, Microplastic, Modelling

JEL classification: Q53, O13

\section{INTRODUCTION}

Marine debris is a global issue that concerns the world because marine debris causes many adverse effects on the marine environment, marine biota and threaten the life-sustenance of humans. Of the various types of waste in the sea, plastic is the most widely found waste (UNEP, 2016). In 2010, recorded from coastal areas in 192 countries around the world produced 275 metric tons of plastic waste, with 4.8-12.7 metric tons of waste entering the ocean (Jambeck, et al., 2015). In Pangandaraan and Biawak Island found that plastics is the most trash (Purba et al., 2017; Purba et al., 2018). In the world, there are several places that are central to the concentration of marine debris, namely the North Pacific, South Pacific, North Atlantic, South Atlantic and the Indian Ocean. Of all the marine debris in the world's oceans, $55.6 \%$ of the total particles and $56.8 \%$ of the total 
plastic waste are in the ocean in the northern hemisphere, where $37.9 \%$ of the particles and $35.8 \%$ of the plastic mass located in North Pacific Ocean. The North Pacific Ocean is the region with the largest concentration of marine waste in the world as there are $199 \times 1010$ pieces of plastic with a total weight of 96,400 tons (Eriksen, et al., 2014), and the number of plastic pieces categorized as microplastic already exceeds the number of planktons in the Ocean with a ratio of 6: 1 (Moore, et al., 2001). This causes the North Pacific Ocean to be nicknamed the "Great Pacific Garbage Patch" (PGP). While in the southern hemisphere, the concentration of marine debris is mostly in Hindia Ocean. The number of garbage particles in the Indian Ocean is more than the combined garbage particles in the South Atlantic Ocean and the South Pacific Ocean.

The important of this research because the microplastic will flows to Indonesia water via several circulation. The first impact is to Coral Triangle area include Raja Ampat and Maluku Sea. Coral Triangle (CT) have sixteen ecoregions of the world have $>500$ species; these define the CT and reveal its internal components to the level or resolution (Veron, et.al 2010). Coral Reef as Ecosystem give many economy benefit to society such as resource for food and tourism. Many groups and cultures rely on local resources for food, livelihoods and raw materials (Pilgrim, et. al 2008). Biodiversity loss and food insecurity are two of the greatest challenges of the $21^{\text {st }}$ century (Rockstrom, et.al 2009).

Coral reef based tourism in the Coral Triangle region is responsible for economic benefits. Tourism, directly or indirectly, accounts for around 10 percent of the world's gross domestic product (US\$7.6 trillion annually), (Huang \& Coelho, 2017). These two issues had related correlation with marine debris. marine debris can disturb waters column, alter the acid or even cover the coral reefs. the coral reef will deaths that result in the decline of the biota that leaves the ecosystem, one of which is the fish as a source of food. The presence of marine debris also disrupt the aesthetic elements of the waters which can reduce the interest of tourists from visiting because the waters are polluted by marine debris.

Laws exist on land and at sea related to litter and debris, as well as other pollution forms. The problems exist and continue due to human-influenced activities that result in pollution being introduced into the environment and economic problem (Sheavly, 2004).

\section{METHODS}

\section{Area of study}

The study areas cover the western Pacific Ocean to the northern waters of Indonesia. This area of research includes coordinates of $32^{\circ} \mathrm{N}-1^{\circ} \mathrm{S}$ and $120^{\circ}-163^{\circ} \mathrm{E}$ as shown in Figure 1. The North Pacific Ocean Region became the beginning of the study area because this region is the center of the largest concentration of marine waste in the world or better known as Great Pacific Garbage Patch (UNEP, 2016). 


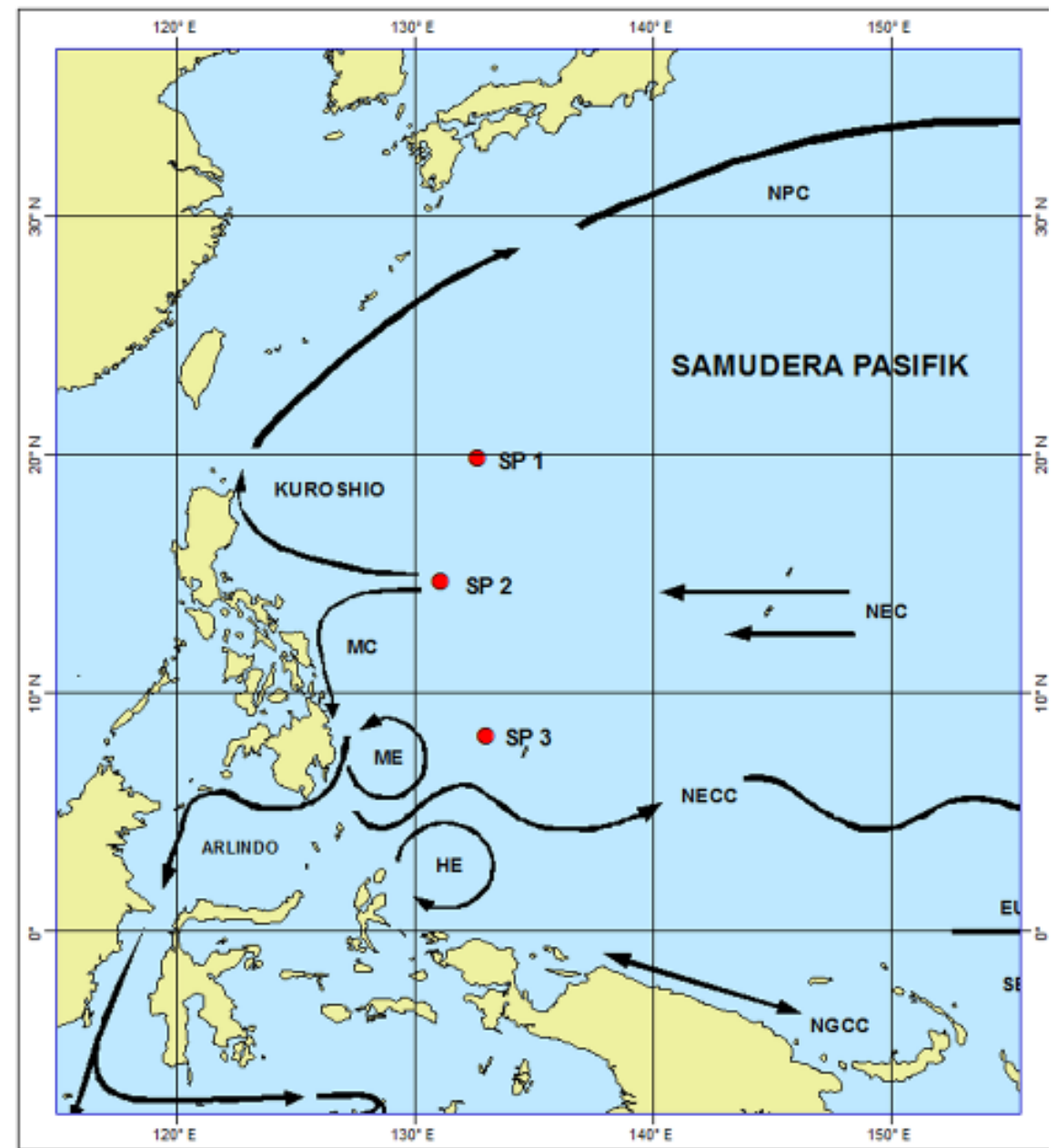

Figure 1. Area of study

\section{Modelling data}

The materials used in this research include marine physical parameter data consisting of current data, bathymetry data, tidal and wind data, and garbage data covering waste type, waste weight and flux of microplastic waste. These data are secondary data obtained from several sources.

Table 1. Data of modelling

\begin{tabular}{cl}
\hline Data & \multicolumn{1}{c}{ Source } \\
\hline Bathymetri & General Bathymetric Chart of The Oceans (GEBCO) \\
Tide & Intergovernmental Oceanographic Commission of \\
& UNESCO (IOC-UNESCO) \\
Wind & $\begin{array}{l}\text { European Centre for Medium-Range Weather Forecasts } \\
\text { (ECMWF) } \\
\text { Marine Debris }\end{array}$ \\
\hline
\end{tabular}

Modeling in this research is done in 2 (two) modeling stage, Hydrodynamic modeling, and Particle Tracking modeling. The first stage is the modeling of hydrodynamics to model the dynamics of seawater in the West Pacific Ocean, Sulawesi 
Seas to Makassar Strait. The second stage is modeling to track the movement of trash particles moving from the Western Pacific Ocean to Indonesian waters. Modeling is done within one year, throughout 2016 with intervals every six hours. Furthermore, modeling results will be analyzed by a descriptive method to see the description of a marine waste phenomenon that occurred within the scope of the research area.

\section{RESULTS AND DISCUSSION}

\section{Oceanography}

In making the modeling of the study area, there are several treatments so that the results of the modeled region may differ from the actual situation. Philippines comprising archipelagic clusters, engineered into a single unity of large islands and some small islands were eliminated. It aims to see the microplastic same movement of the Pacific Ocean without anyone entering the Philippines archipelago and focusing on its northerly movement (Kuroshio influx) and the southward movement (the influence of Mindanao Stream).

The Indonesian archipelago is also undergoing an engineering process, one of which is the removal of several small islands leaving only the major islands, namely Kalimantan, Sulawesi, Papua, and Maluku. Unlike the Philippines, the archipelago is not united as a single island. It aims to not close the path of microplastic waste from the Pacific Ocean to Indonesian waters. The water mass from the Pacific Ocean assumed to carry microplastic waste can enter Indonesia through the ARLINDO line that includes the Maluku Sea, Sulawesi Sea and Makassar Strait (Feng et al., 2018).

Since early 2016, the wind speed at an average $3-10 \mathrm{~m} / \mathrm{s}$ blown from the northeast. The graph shows the peak of West Monsoon occurred at the end of January 2016 with wind speed reaching $10.95 \mathrm{~m} / \mathrm{s}$. The average speed of the wind began to decline from February to May, then the average wind speed began to rise again in June. The graph shows the wind blowing hard to reach its peak in early August with wind speeds reaching $10.83 \mathrm{~m} / \mathrm{s}$. This may indicate an East Monsoon peak early in August, but then the wind speed weakens to just blowing at a rate of $0.05 \mathrm{~m} / \mathrm{s}$, which is the lowest instantaneous wind speed in 2016. This is in line with research (Wyrtki, 1961), which states that the peak of Western Monsoon an-gin formation occurred in January, while the peak of the East Monsoon wind formation occurred between July and August.

\section{Particle trajectory}

The trajectory simulation of microplastic particles is carried out for 365 days with a span of time every 6 hours. A microplastic particle is assumed to have a weight of $0.01 \mathrm{mg}$. During simulation, the source point is assumed to emit particles as much as $50 \mathrm{mg}$ per second.

The Trajectory of particles on Start Point (SP) 1 can be seen in Figure 2. The point of SP1 is at coordinates $18^{\circ} \mathrm{N} 132^{\circ} \mathrm{E}$. The simulation results show that the pattern of microplastic movement on SP1 moves predominantly to the northeast and southwest and forms a vortex clockwise (anti-cyclone). This circular motion pattern occurs continuously throughout the year. The microplastic in SP 1 is more dominantly moving towards the northeast because the Pacific Sub-tropical Flow Flow plays a dominant role in driving the microplastic movement, the dominant movement to the southwest as it is influenced by the Pacific Wind, whereas the circular motion pattern that occurs because SP 1 is still affected by the intersection between the Pacific Sub-Tropical Flow of the Pacific and the Pacific Equatorial Flow so as to form the vortices clockwise. 

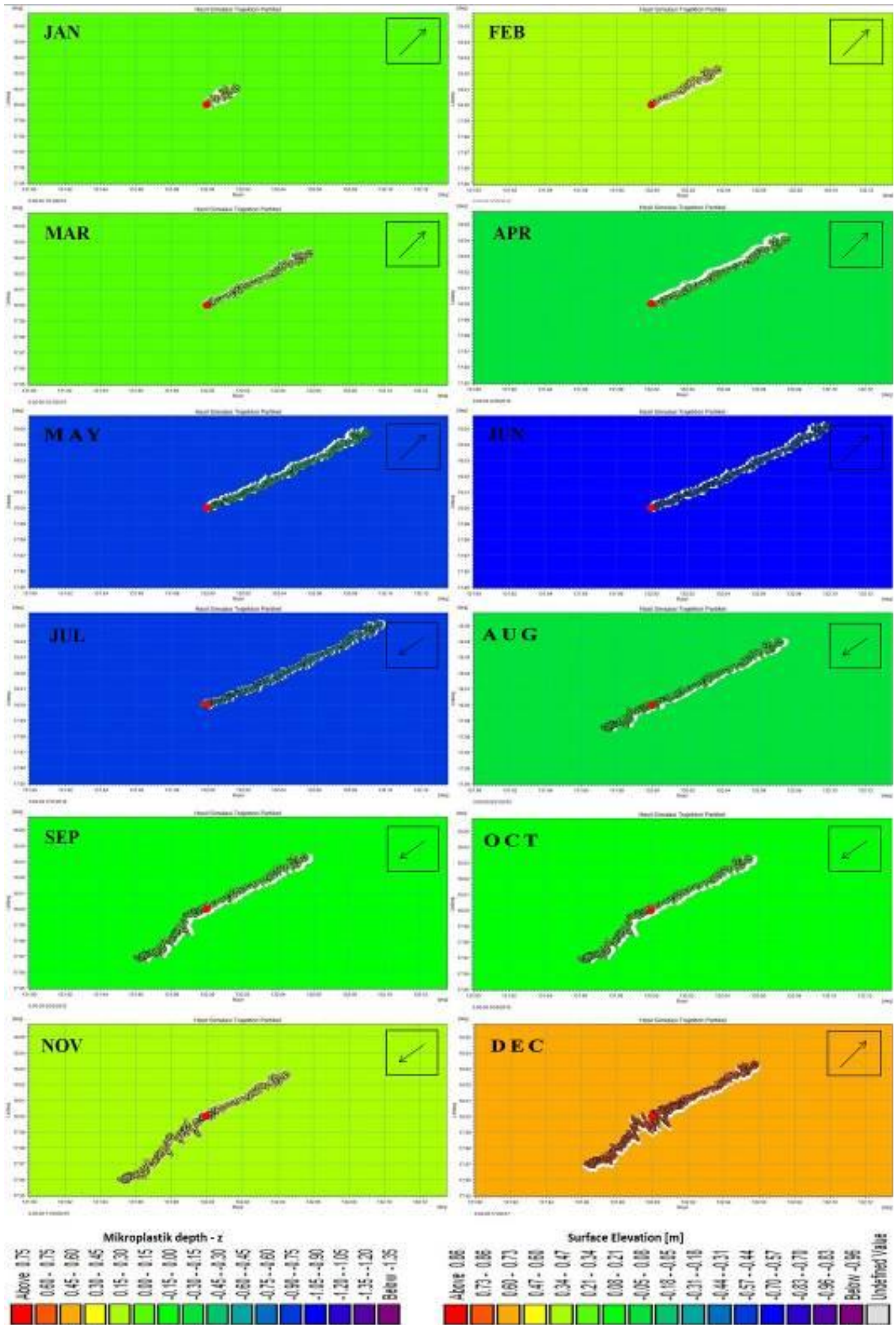

Figure 2. SP1 Simulation Result on Jan-Dec 2016

Start Point 2 (SP2) is the source point located at coordinates $14^{\circ} \mathrm{N}-131^{\circ} \mathrm{E}$, where this point represents waste from the most western Great Pacific Garbage Patch. The visualization of the result of the simulation of the particle trajectory on SP2 can be seen in Figure 3. 

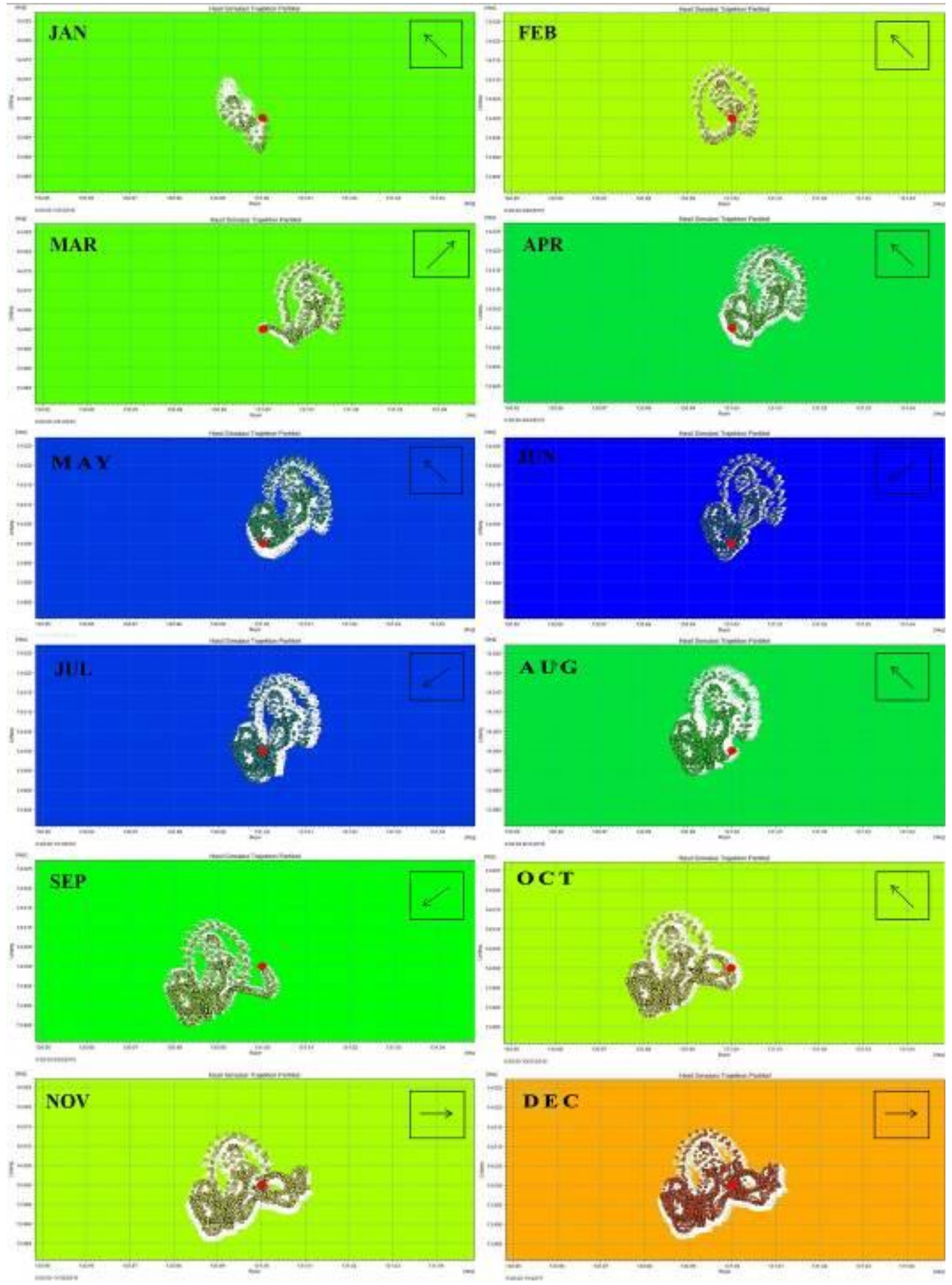

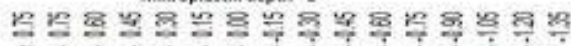

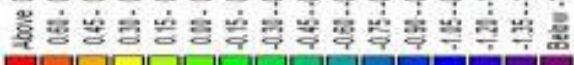

Figure 3. SP2 simulation result on Jan-Dec 2016

The simulation results show that the pattern of microplastic movement in SP 2 forms a vortex clockwise (anti-cyclone). This circular motion occurs continuously throughout the year. This is because SP 2 is in the path of the current 2 currents, the Pacific Equatorial Flow and the Pacific Sub-Tropical Flow Flow. The Pacific Equatorial Current takes the mass of water to the west, whereas the Pacific Sub-Tropical Flow Flow brings the mass of water to the east so that the crosses between these two currents 
will create a clockwise whirlpool. This affects the pattern of microplastic movement in SP 2 to be circular motion.

Start Point 3 (SP3) is a source point located at coordinates $8^{\circ} \mathrm{N} 132^{\circ} \mathrm{E}$, where this point represents trash coming from the southernmost Great Pacific Garbage Patch. Visualization of simulation result of particle trajectory on SP 3 can be seen in Figure 4.
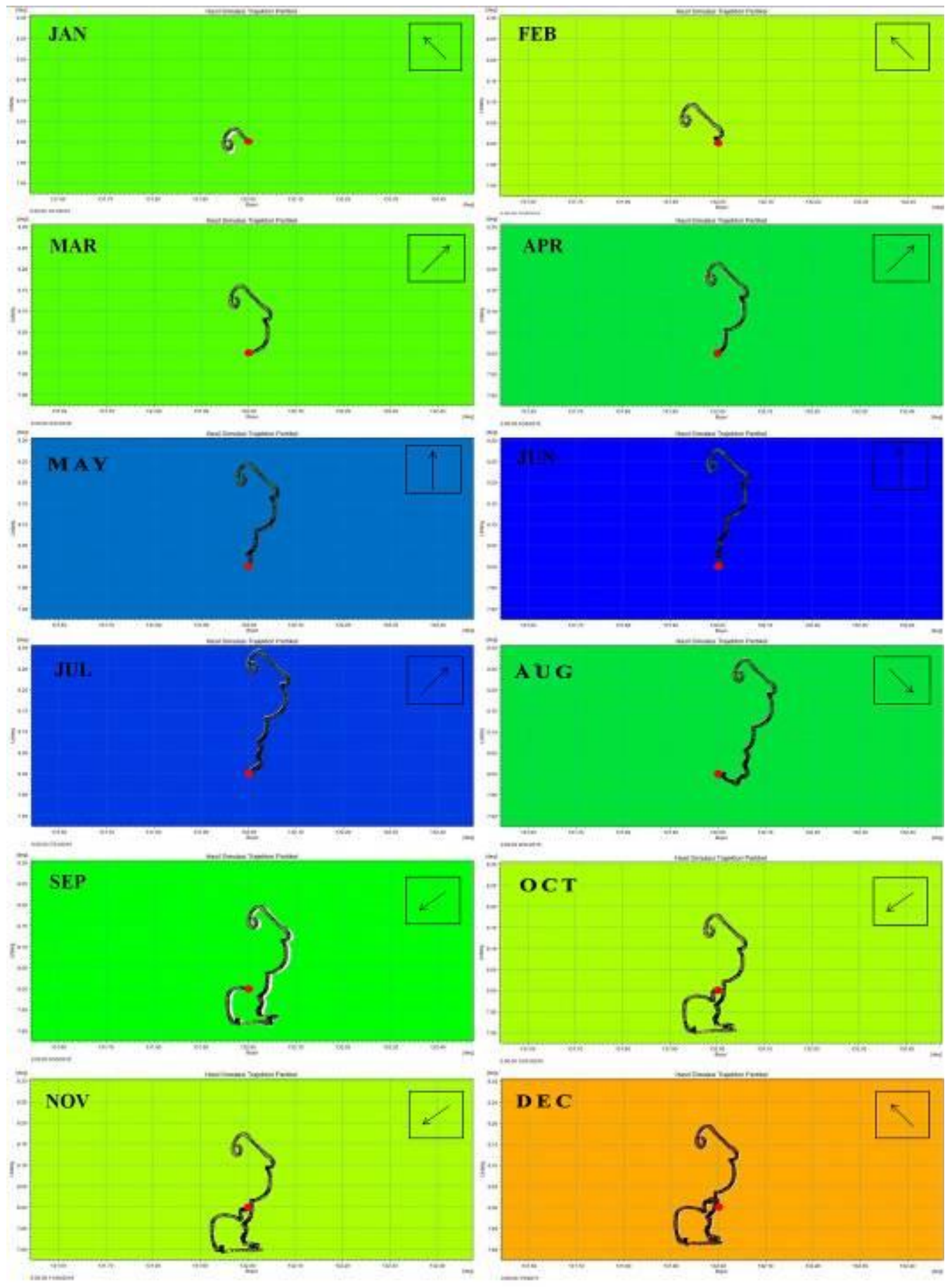

Mikroplastik depth - $x$

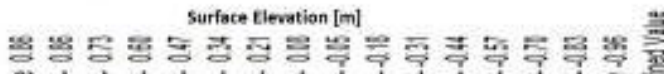

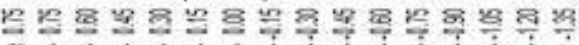

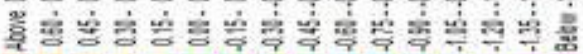

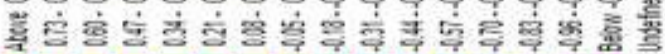

Figure 4. SP3 simulation result on Jan-Dec 2016 
The simulation results show that the pattern of microplastic movement in SP 3 shows a fluctuating movement. In January - July, the microplastic tends to move northward. Then in August - November, microplastic particles tend to move towards the southwest. The direction of fluctuating movement is due to the microplastic movement following the different changes of wind direction each season, ie West Wind Monsoon, East Monsoon Wind and Pacific Wind.

The results of the particle trajectory simulations illustrate very different trajectories and movement patterns at each source point of microplastic waste. This is because each source point is on a different path of ocean currents. Point SP 1 is in the path of the Pacific Sub-tropical Backflow, the point SP 2 is at the point of intersection between the Sub-tropical Flow with the Pacific Equatorial Flow, and the point SP 3 is on the Mindanao swirl trajectory. This shows that ocean and wind currents are very influential in the movement and pattern of marine waste distribution (UNEP, 2016).

Ocean debris could ended up in shoreline and makes unattractive and hazardous, and can inhibit tourism. it can also reduce local community's finances, with increased beach maintenance costs. The indirect costs, though, are perhaps even greater. Its presence discourages people from partaking in coastal activities, such as recreational fishing, boating, swimming, or beach going. It even reduce tourists from visiting coastal areas. Most coastal communities rely on seaside businesses for their economic survival (Sheavly, 2004). The presence of debris can losses economy revenue from national and local activities and the marine environment. These impacts can be costly, in case of Goeje Island in Korea loses 29-37 million euro in 2011, from fishing activities 250 million US Dollar from global catch per year (Watkins et al., 2015)

\section{CONCLUSIONS AND RECOMMENDATIONS}

\section{Conclusions}

Based on the results of the research and discussion conducted, the conclusions can be taken, ie Simulation of the trajectory of the particles shows the furthest microplastic displacement from the source point on the SP 1 is $3.17 \mathrm{~km}$, the SP 2 is 1.35 $\mathrm{km}$ and the SP 3 is $8,94 \mathrm{~km}$. Simulation of the trajectory of microplastic particles for 1 year showed that the microplastic waste sourced from Great Pacific Garbage Patch did not reach the northern waters of Indonesia. But, with the widespread of research in marine debris, the impact of marine debris would be impacted into tourism, fisherman activities, local income especially in east Indonesia with the high diversity of fish and ecosystem.

\section{Recommendations}

More complete data is needed, including the data of marine debris found in Pasific Garbage Patch so the determination process of Start Point in the model can be closer to real condition. Longer timelapse modeling and more Start Points are needed to see the comprehensive movement of marine debris. Also, the comprehensif review and research aboout economic loss from marine debris in coastal area. 


\section{ACKNOWLEDGMENT}

The authors would like to acknowledge anomin Reviewer for this paper and Archipelago Province Future Workshop held by Universitas Padjadjaran in 2017 for paper presentation.

\section{REFERENCES}

Eriksen, M., Lebreton, L., Carson, H., Moore, C., Thiel, M., Borerro, J., Galgani, F., Ryan, P., and Reisser, J. (2014). Plastic Pollution in the World's Ocean: More than 5 Trillion Plastic Pieces Weighing over 250,000 Tons Afloat at Sea. PLoSONE, 1-15.

Feng, M., Zhang, N., Liu, Q., Wiffels, S. (2018). The Indonesian troughflow, its variability and centennial change. Geosciense Letter, 5(3), 1-10.

Huang, Y., Coelho, V.R. (2017). Sustainability performance assessment focusing on coral reef protection by the tourism industry in the Coral Triangle region. Tourism Management 59. pp 510- 527.

Jambeck, J. R., Geyer, R., Wilcox, C., Siegler, T. R., Perryman, M., Andrady, A., Narayan, R., \& Law, K. L. (2015). Plastic Waste Inputs from Land into the Ocean. Science, 347(6223), 768-771.

Moore, C., Moore, S., Leecaster, M., \& Weisberg, S. (2001). A Comparison of Plastic and Plankton in the North Pacific Central Gyre. Marine Pollution Bulletin.

Pilgrim, S.E., Cullen, L.C., Smith, D.J., Pretty, J., (2008). Ecological knowledge is Lost in Wealthier communities and Countries. Environ. Sci. Technol. 42, 10041009.

Purba, N.P., Syamsudin, M.L., Sandro, R., Pangestu, I.F., Prasetio, M.R. (2017). Distribution of Marine Debris in Biawak Island, West Java, Indonesia. World Scientific News, 66, 281-292

Purba, N.P., Apriliani, I.M., Dewanti, L.P., Herawati, H., Faizal, I. 2018. Distribution of Macro Debris at Pangandaran Beach, Indonesia. World Scientific News, 103, 144-156

Rockstrom, J., Steffen, W., Noone, K., Persson, A., Chapin, F.S., Lambin, E.F. (2009). A safe operating space for humanity. Nature (London). 461:472-475.

Sheavly, S.B. (2004). Marine debris, and Overview of critical issue for our oceans. APEC Marine Debris Seminar, Hawaii. 1-8.

Turgeon, A. (2014). Great Pacific Garbage Patch. Retrieved Oktober 31, 2016, from www.nationalgeographic.org

UNEP. (2016). Marine Plastic Debris and Microplastic - Global Lessons and Research to Inspire Action and Guide Policy Change. United Nations Environment Programme.

Veron, J.E.N., DeVantier, L. M., Turak, E., Green, A. L., Kininmonth, S., StaffordSmith M., Peterson, N. (2010). The Coral Triangle. DOI Number: 10.1007/97894-007-0114-4_5

Watkins, E., Brink, P., Withana, S., Mutafoglu, K., Schweitzer, J.P., Russi, D., Kettunen, M. (2015). Marine Litter: Socio-economic study: Scoping Report. 
Institute European Environmental Policy. Pp22

Wyrtki, K. (1961). Physical Oceanography of the Southeast Asian Waters. California: The University of California. 